to lower-crustal depths in the region). Their data also imply that the metamorphism occurred relatively recently no more than 30 million years ago. Hayob et al. interpret the distribution of xenolith localities to indicate that the granulitegrade metamorphic event was regional in extent (at least $100 \mathrm{~km}^{2}$ in area and perhaps extending for more than a thousand kilometres to the north). The heat source is inferred to be underplated basaltic magma, small volumes of which reached the surface as the xenolith-bearing basanites. The authors emphasize their evidence for the lack of a protracted history of cooling of the xenoliths (to temperatures less than $900{ }^{\circ} \mathrm{C}$ ), and the fact that basaltic magmatism continues to be active in the region. They use these observations to postulate that granulite-facies metamorphism continues even now in southern North America.

Hayob et al. suggest that the lower crust can contain supracrustal rock types; that, in this case, the lower crust is granulitic; that granulite-facies metamorphism can be powered by mantle heat through basaltic underplating away from mountainbuilding (orogenic) settings; and that these processes are still continuing. None of these ideas or general observations (except for the extreme temperatures and limited retrograde cooling) is uniquely that of the authors. Their contribution lies in documentation and in the recognition of the collective importance of the separate pieces of data. The authors' arguments need some strengthening, particularly by the application of different age-dating techniques to xenolith mineral assemblages and integration with structural, tectonic and geophysical observations. But even as it stands, the evidence is sufficiently strong to make waves in the sea of geological opinion.

In the short term, the debate is unlikely to settle down. Granulite-facies metamorphism does occur over a broad range of conditions $\left(700-1,100{ }^{\circ} \mathrm{C} ; 400-1,500\right.$ megapascals; water activity $0-0.7$ ) in varied tectonic settings. This suggests that a great variety of materials and processes are involved. The task ahead is to determine which are actually involved and which are most important. I expect that the underplating mechanism, combined with partial-fusion reactions in the absence of fluids, will turn out to be a principal factor in granulite-facies metamorphism, growth and differentiation of the crust, and the origin of upper-crustal granitic rocks. In an even broader context, I believe that core-mantle boundary instabilities, mantle plumes, anomalous conductivity in the lower crust, continental rifting, flood basalt outpourings and major biological events will all eventually come to be linked with these lower-crustal processes, operating on supracrustal rocks, in the same complex, discontinuous chain of events.

J.D. Clemens is in the Depatment of Geology, Manchester University, Manchester M13 9PL, UK.

\title{
Gibbons swing stress away
}

\section{R. McNeill Alexander}

A FORCE acting on the end of a bone, parallel to its long axis, sets up stresses that are uniform across each cross-section. A force at right angles to the bone exerts bending moments on it, setting up tensile stresses in one face of the bone and compressive stress in the opposite face. When mammals run, the stresses in their bones are mainly due to bending moments. But when gibbons brachiate, swinging

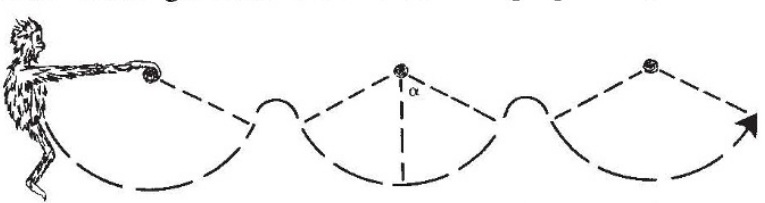

loads. The radius, however, experiences bending moments because it is curved and is pulled on by the muscles that hold the fingers hooked over the branch.

A given force sets up much larger stresses in bones (or other long, slender structures) if it acts at even quite a small angle to the shaft than if it acts precisely axially. Gibbons can make do with remarkably slender arm bones because they load them axially: the humerus, for example, is 1.7 times as long as predicted for typical primates of the same body mass, but barely thicker than predicted ${ }^{2}$.

from branch to branch by their arms, the stresses in two of the principal arm bones are tensile right across the shaft, according to measurements reported by Sharon Swartz and her colleagues on page 270 of this issue'. By attaching strain gauges to the bones of captive gibbons and recording, by radiotelemetry, the strains during brachiation, they found that the humerus and ulna experience almost axial tensile

Compare a gibbon of mass $m$ and arms of length $l$, with a biped of the same mass and with legs also of length $l$. Suppose that the gibbon reaches out to a branch that is level with its shoulder and starts swinging. In the initial downswing it loses height $l$ and gains speed $v$. The lost potential energy is converted to kinetic energy, so $v=\sqrt{2 g l}$. The gibbon reaches this maximum speed in each swing, but its mean speed over a complete cycle of brachiation depends on the angle of swing, $\alpha$ (see figure). For $\alpha=90^{\circ}$, the mean speed is $0.5 \sqrt{g l}$ (calculated as in ref. 3); for small values of $\alpha$, it approaches $1.4 \sqrt{\mathrm{gl}}$. The force transmitted by the arm at the bottom of each swing is the weight plus the centripetal force, $m g+\left(m v^{2} / l\right)=$ $3 \mathrm{mg}$. If the arm is kept straight, the load on the bones is axial.

Our theoretical biped could maintain the axial load on its bones by keeping the supporting leg straight, as walking people do, but the axial load would be compressive rather than tensile as in the gibbon arm. Long leg bones could not be very slender or they would buckle under this load. Also, a biped using a straight-legged walk could not travel faster than $\sqrt{g l}$ because higher speeds would require downward accelerations greater than gravitational $g$ (ref. 4). To travel faster, the biped would have to run, bending the legs at the knee and exposing the bones to bending moments. The peak force on a human runner's foot is about $2.8 \mathrm{mg}$, almost the same multiple of body weight as on the hand of our theoretical gibbon; but our theoretical biped would need leg bones thicker than the gibbon's arm bones to withstand the bending moments.

What would happen if the gibbon and the biped evolved longer limbs? By the argument already presented, the gibbon's speed would increase in proportion to the square root of its arm length. Similarly, the biped would increase speed in proportion to the square root of its leg length if it maintained dynamic similarity of gait $^{5}$. In both cases the forces on the limb would remain unchanged, but the bending moments would increase in the biped in proportion to leg length. The longer-armed gibbon has no need for its bones to be thicker but the longer-legged biped does need thicker bones.

Gibbons are not limited by the speed they can gain in the first swing, but can accelerate by using leg movements like a child 'pumping' a swing 6 . They could accelerate faster by bending and extending the supporting arm instead of the legs, at appropriate stages of the swing, but that would result in bending moments. The penalty for relying on slender tensile arms is poor acceleration.

Finally, the really bad news, gibbon bones often get broken?

R. McNeill Alexander is in the Department of Pure and Applied Biology, University of Leeds, Leeds LS2 9JT, UK.

1. Swartz, S.M., Bertram, J.E.A. \& Biewender, A.A. Nature 342, 270-272 (1989)

2. Aiello, L.C. Symp. zool. Soc. Lond. 48, 331-358 (1981)

3. Preuschoft, H. \& Demes, B in The Lesser Apes (eds Preuschoft, H. Chivers, D. J., Brockelman, W.Y. \& Creel, N.) $96-118$ (Edinburgh University Press, 1984).

4. Alexander, R. McN. Am. Sci. 72, 348-354 (1984).

5. Alexander, R. MCN. \& Jayes, A.S. J. Zool. Lond. 201, 135 152 (1983).

6. Fleagle, J. Nature 248, 259-260 (1974).

7. Schultz, A.H. Bull. Hist. Med. 7, 571-582 (1939) 